\title{
Bisphenol A (BPA) in Thermal Paper Used for Receipts
}

\author{
Rebecca Wong ${ }^{1}$, Vanessa Karakilic ${ }^{2}$, Kevin Soulsbury ${ }^{3}$
}

${ }^{1}$ Lead Author and Researcher, B. Tech Student, School of Health Science, British Columbia Institute of Technology, 3700 Willingdon Ave, Burnaby, BC V5G 3H2

${ }^{2}$ Supervisor, School of Health Science, British Columbia Institute of Technology, 3700 Willingdon Ave, Burnaby, BC V5G3H2

${ }^{3}$ Contributor, School of Computing and Academic Studies, British Columbia Institute of Technology, 3700 Willingdon Ave, Burnaby, BC V5G 3H2

\begin{abstract}
:
Background: Bisphenol A (BPA) is a proven endocrine disruptor and has been found in the urine of $95 \%$ of Canadians. Though the chemical has been banned for use in certain applications, it is still common in items such as thermal paper used for receipts because the compound is heat stable. This study aims to determine if the levels found in thermal receipt paper are high enough to pose a public health concern.
\end{abstract}

Methods: Samples of thermal paper used for receipts were tested for BPA by soaking and incubating $100 \mathrm{mg}$ of the paper in $10 \mathrm{~mL}$ of methanol for 3 hours at room temperature, and then overnight at $4^{\circ} \mathrm{C}$. The resulting methanol solution was then analyzed by using an HPLC (high performance liquid chromatography) system with fluorescence detection.

Results: A total of 30 receipts were tested from various stores around the Lower Mainland, including retail stores and restaurants. Of the 30 samples, 13 tested positive for bisphenol $\mathrm{A}$, and of those 13 , the amount ranged from 0.124 to $871.17 \mathrm{mg} \mathrm{BPA}$ per $\mathrm{kg}$ paper. Using the provisional total daily intake $(0.025 \mathrm{mg} / \mathrm{kg}$ body weight/day) set by Health Canada in 1996, results indicate that there can be enough BPA present in a minimum of 2 grams of the paper to exceed the daily limit for a person weighing $70 \mathrm{~kg}$. However, the human body does not absorb all of the BPA it may come into contact with, nor does a person touch the entire surface of the paper; thus, more than 2 grams of thermal paper would be required to actually exceed the pTDI.

Conclusion: Although the human body does not absorb all of the BPA it may come into contact with, thermal receipt paper can still be a significant source of BPA, especially for those who handle them frequently, such as cashiers. Public education on common sources of BPA, such as thermal receipts, would reduce exposure.

Keywords: bisphenol A, BPA, thermal paper, retail receipts 


\section{INTRODUCTION}

Bisphenol A (BPA) is used in many everyday applications, especially in hard plastics. This can include containers, such as water bottles, baby bottles and the inside lining of canned foods, as well as electronics, sports safety equipment and thermal paper used for receipts (1).

Instead of a conventional ink or toner printer, many companies make use of thermal printers for the advantages it has over its counterparts. Thermal printers are generally faster, quieter, cheaper and have fewer moving parts (2). These printers do not require ink; the print heads heat up, which causes a chemical reaction on the specially coated paper and causes specific portions to change colour when exposed to heat (2). One of these chemicals is BPA; it is used because it is "extremely stable and heatresistant" (3).

Receipts from retail stores are ubiquitous and many people handle them daily, affecting a large percentage of the population. There is evidence that BPA can be absorbed through the skin, and the "use of hand sanitizers and other skin care products, including soaps, lotions and sunscreens" (4) may enhance the absorption due to certain properties.

\section{EVIDENCE REVIEW}

BPA is classified as an endocrine disruptor, which is an "exogenous substance that causes adverse health effects in an intact organism or its progeny, consequent to changes in endocrine function" (5, p49). Under this umbrella term, it is further classified as a xenoestrogen, which is a synthetic version of the hormone estrogen. The effects of BPA as a drug were never tested, as another chemical (diethylstilbestrol) was used in its place, but nevertheless, BPA has made its way into our environment (3).

Though BPA was first synthesized in 1891, it was never used commercially as the "estrogenic substance" that Dr. Charles Dodd was looking for, but instead, was used in plastics. It was first used in the 1950s and it was discovered that BPA could be used to form a hard and clear plastic called polycarbonate (6). It is now being produced at about 15 billion pounds per year (4).

Many household items contain components made with BPA, and it has been found that the chemical "is entering the environment through wastewaters, washing residues and has been found in some leachate from landfills" (7). In addition, BPA has been found in $73 \%$ of canned foods, the source being the lining of the can (1).

According to a study done by Statistics Canada (8), BPA can be found in the blood or urine of 95\% of Canadians. The study looked at a "nationally represented sample of Canadians aged 3 to 79 years from 18 collection sites" (8). An average of $1.2 \mu \mathrm{g} / \mathrm{L}$ of BPA was found, and the concentration did not differ significantly between age groups, gender, education level, household income or body mass index. 


\section{BPA in Thermal Receipt Paper}

Because of its chemical characteristics, BPA is used in thermal paper as a developer. It is stable and heat resistant which makes it the ideal chemical for thermal printing (3).

In an American study, it was found that retail workers have higher levels of BPA found in their urine (9). Retail workers were in contact with receipts all day, and thus the level of BPA found on their hands was higher than the average person.

A study done in 2010 (10) on samples of thermal paper from various shops showed that 11 out of 13 samples contained an average of $13.3 \mathrm{~g} / \mathrm{kg}$ of $\mathrm{BPA}$. The receipts that tested positive were touched to three fingers of their subjects for 30 seconds; the fingers were then submerged in ethanol to extract the BPA. Results showed that an average of $1.13 \mu \mathrm{g}$ was extracted from a finger touching the BPA-coated side of the paper. If the fingers were greasy or wet, the skin was able to pick up even more of the chemical. The study also measured the amount of BPA after 2 hours to measure the absorption through the skin; it was calculated to be $0.09 \mu \mathrm{g}$ of BPA per hour and finger.

Another study showed that lotions and hand sanitizers could increase the absorption rate of BPA through the skin because these products contained "dermal penetration enhancement chemicals" $(4, \mathrm{p} 2)$.

\section{Effects of BPA on Human Health}

According to Rubin (1), BPA does not cause any one disease in particular, but it can be related to many different diseases. It has been linked to "diabetes, cardiovascular disease and altered liver enzymes" (1, p29). As well, it has an effect on reproduction in both men and women. In men, it can affect the DNA and decrease the quality of sperm. In women, the effects differ, depending on age and lifestyle. A correlation was found between BPA levels and recurrent miscarriages, increased premature deliveries in those who undergo in-vitro fertilization, and increased inflammation and oxidative stress in postmenopausal women (1).

Not only can BPA directly affect a person's health, but a study also showed that it could affect unborn children. It followed 389 women who gave birth to single children in 2009 , and suggested that the children who were exposed to BPA prenatally could be more prone to "externalizing behaviours in 2-year-old children, especially among female children" (11, p1950); this was measured with hyperactivity and aggression scales.

\section{Regulations in Canada}

Currently, Canada has "not expected [BPA] to pose a health risk to the general population, including newborns and young children" (12). Using data gathered from experiments, Canada had set a provisional tolerable daily limit (pTDI) of $25 \mu \mathrm{g} / \mathrm{kg}$ body weight/day in 1996 . This number was reviewed in 2008 due to concerns arising from new studies but it was not changed; it was only concluded that more studies needed to be done (12).

Despite this, Canada was one of the first countries to put a ban on BPA in certain 
products. To protect a vulnerable population, the "importation or sale of bisphenol $\mathrm{A}$ in bottles and food packaging for infants and newborns" (13, p1020) was prohibited in 2008.

Environment Canada is considering implementing a maximum allowable concentration of BPA that can be released in the environment, as well as other best management practices for the industries that use the chemical (8).

\section{Limitations of the Study}

The fact sheet provided by the Government of Canada (14) states that the average level of exposure to the general public is not harmful. It acknowledges that newborns and infants should be the focus of safety regarding BPA due to some uncertainty that some studies have shed. Subsequently in 2008, Canada has banned the use of BPA in baby bottles under the Canada Consumer Product Safety Act, though it is still allowed in food packaging.

BPA awareness in the past few years has led consumers to be more knowledgeable about the products they are purchasing; companies themselves have proactively pulled these items off the shelves. Some companies have also already made the switch to BPA-free thermal paper, which has reduced the sources of BPA.

The purpose of this study is to determine if the levels of BPA present in thermal receipt paper are high enough to pose a health risk to the general public through repeated exposure.

\section{METHODS}

The method used to determine the amount of BPA in thermal paper is a modified methodology from the Extended Application Note Bisphenol A by MicroSolv. The paper suggested that a $200 \mathrm{mg}$ sample of paper be incubated in $20 \mathrm{~mL}$ of methanol for three hours at room temperature (15). Due to the supplies available, this was scaled back by half to $100 \mathrm{mg}$ of sample in $10 \mathrm{~mL}$ of methanol. The sample was then incubated for 3 hours at room temperature as described but due to time constraints, the samples were placed in the refrigerator at $4^{\circ} \mathrm{C}$ overnight before testing.

The resulting methanol solution was placed in an autosampler vial and run through an HPLC (high performance liquid chromatography) system with a fluorescence detector instead of using a variable wavelength UV detector as in the paper by MicroSolv (15). If the resulting concentration was too high for the HPLC system to read, the methanol solution was further diluted by taking $10 \mu \mathrm{g}$ of the sample and making it up to $1 \mathrm{~mL}$ with methanol; for the few samples that required even further dilution, $1 \mu \mathrm{g}$ of the previously diluted solution was made up to a $1.75 \mathrm{~mL}$ solution with methanol.

\section{RESULTS}

The amount of BPA found during this study is not as high as the numbers found in previous studies. The highest amount of BPA found was $0.61 \mathrm{~g} / \mathrm{kg}$ of paper while other studies found 
amounts from an average $13.3 \mathrm{~g} / \mathrm{kg}(10)$ to about $20 \mathrm{~g} / \mathrm{kg}(4)$, and $9-21 \mathrm{~g} / \mathrm{kg}$ (16).

A factor that could contribute to the discrepancy between the amount of BPA found in this study and other studies is due to when the studies were completed. Some of the studies were completed in 2010 (10) and 2012 (16), and may not reflect the market change towards using thermal receipt paper that has a lower, or no levels of BPA.

Another study was conducted in Switzerland (17), and may not be indicative of the North American market use.

\section{Statistics}

The type of data gathered in this project is continuous numerical data. It is a measure of the amount of BPA in the receipt paper and measured in parts per billion. The number will be converted to grams per kilogram $(\mathrm{g} / \mathrm{kg})$ and then compared to the provisional total daily intake set by Health Canada in 1996 (12) for a person weighing $70 \mathrm{~kg}$.

The descriptive statistics of the levels of the BPA measured by the HPLC system were analyzed through Microsoft Excel, as show in Table 1.

Table 1: Descriptive Analysis Report

\begin{tabular}{|l|l|}
\hline Mean & $0.01695 \mathrm{mg} /$ day \\
\hline Standard Error & $0.00518 \mathrm{mg} /$ day \\
\hline Median & $0 \mathrm{mg} /$ day \\
\hline Mode & $0 \mathrm{mg} /$ day \\
\hline Standard Deviation & $0.028374 \mathrm{mg} /$ day \\
\hline Sample Variance & $0.000805 \mathrm{mg} /$ day \\
\hline Kurtosis & $0.237645 \mathrm{mg} /$ day \\
\hline Skewness & $1.337129 \mathrm{mg} /$ day \\
\hline
\end{tabular}

The inferential statistics were analyzed through NCSS 10. A one-tailed one sample t-test will be performed to compare the mean amount of BPA in the samples of thermal paper to the pTDI set by Health Canada (12). A one-tailed one sample $t$-test was performed because it is assumed that the mean amount of BPA found in the thermal paper samples will be lower than the pTDI.

According to the results, the data is not normally distributed and that the null hypothesis (the levels of BPA found in $100 \mathrm{mg}$ of thermal paper are equal to or less than the pTDI set by Health Canada) cannot be rejected due to the p-value being 0.500 .

\section{DISCUSSION}

Taking into account Health Canada's provisional total daily intake of $0.025 \mathrm{mg} / \mathrm{kg}$ body weight/day (12), and assuming an average body weight of $70 \mathrm{~kg}$, a person may be safe if exposed to $1.75 \mathrm{mg}$ of BPA or less per day.

The amount of BPA that was found in some of the thirty receipts tested contains an amount that would easily add up to $1.75 \mathrm{mg}$ over the course of a day especially if it is part of a person's daily routine. For example, taking in the highest detected amount from this study, about 2 grams of that particular brand of paper carries enough BPA to exceed the pTDI. To absorb that amount of BPA, however, would require more than 2 grams of paper because not $100 \%$ of the chemical is absorbed (4). The exact amount would also depend on how much of the receipt is contacted, and for how long, as well as any lotions or sanitizers on the person's skin (4). 
The numbers gathered in this study indicates that the danger of BPA in thermal paper is not as big a concern for the general public as it could be for retail workers who handle the paper on a daily basis.

\section{RECOMMENDATIONS}

Education of workers, such as cashiers, could be done to limit their exposure to BPA.

Information could be spread on how to avoid touching the receipts by wearing gloves, or if they cannot wear gloves, inform them that having lotions and sanitizers on their hands would increase their absorption of the chemical. It would be important to emphasize that handwashing before eating would help eliminate some of the BPA.

It can also be recommended that stores move to, or at least provide the option for customers to have their receipts emailed to them to avoid using any paper at all. This system has been in place in many retail outlets such as Macy's in the United States. However, this is not an option in many places, such as small independent stores that do not have the money for the infrastructure required. Also, many people are opposed to this system as it they are weary of their information being available online. If this is not possible, it can be recommended that stores make the switch to BPA-free alternatives.

Health Canada, or other related agencies, should also research and create a total daily intake number that is not just a provisional number based on previous studies. The numbers that were used in creating the pTDI were from 1996 and Health Canada themselves have recommended that further research be completed (12). Health Canada could also consider banning BPA and similar chemicals in receipts, like they have done with baby products (13). This has already been done in Suffolk, New York (18).

\section{LIMITATIONS}

Although this research aimed to measure the amount of BPA that may be in a receipt, it is limited by many factors.

\section{Amount of BPA}

The amount of BPA found per receipt is only a measure of what was in a $100 \mathrm{mg}$ sample of the receipt. That, in and of itself, is not representative of the entire receipt length, nor how much surface area a person contacts. This amount was chosen due to the equipment available in the chemistry lab at the British Columbia Institute of Technology.

The data also is not representative of the amount that gets absorbed by the body; this amount also varies from person to person, depending on the substances they touched before handling the receipt, substances on their hands as they touch the receipt and what they do with their hands after touching the receipt. The measurement of how much BPA was absorbed is limited by the fact that BCIT does not allow for testing of blood or urine.

Conducting this study with no knowledge as to whether the receipts tested actually contained 
BPA placed a lot of faith in the method chosen to detect BPA. Results were consistent between runs, but the amount could not be compared to what the label on the boxes of thermal paper claim. To limit this, the paper could have been spiked with a solution containing a known amount of BPA. However, there was no research to indicate if this would be an accurate representation of how BPA is spread over receipt paper.

\section{Standard Methods}

There was no consensus on a standard method to perform the analysis of BPA in thermal paper across many different studies, which could lead to inconsistent results. The method used in this research was a method that modified an existing method by MicroSolv (15) to provide consistent results; this could have led to an undetected error.

\section{Bias}

The receipts that were collected may not have been representative. They were chosen solely based on being the first thirty that the researcher managed to acquire, whether through their own daily routines, or through colleagues who were thoroughly coached not to contaminate the receipt and given envelopes to store the receipt in. It would have been more representative to have chosen receipts that were not part of the researcher's every day routine. For example, it would have been more representative if there were an equal amount of receipts from grocery stores as there were from sporting goods stores; in this research, there were more receipts from grocery stores than sporting goods stores.

\section{FUTURE RESEARCH}

A study could be conducted, concentrating on the population that handles thermal receipts as part of their daily routine, or a study could be conducted on different sources of BPA than receipt paper, such as bandages or feminine hygiene products because there is much more contact time, and how that affects human health.

Another study that could be done is whether the printing on the back of a receipt, such as a statement outlining the return policy of that store, affects the BPA levels in the receipt, or if the BPA is only used on the side exposed to the thermal print head.

A survey could be done on how well people would receive e-receipts and if not, what their concerns are or how it could be addressed before they feel comfortable enough for it to be commonplace.

Research could also be done on substances used to replace BPA. For example, it is common to replace BPA with a chemically similar compound, called bisphenol-S (BPS); this compound has similar effects on human health has BPA (18). Looking at the data produced, there is an indication that there is a common substance across most of the receipt paper that did not test positive for BPA. A chemical at a very similar wavelength - at around 3.5 as opposed to BPA's 3.370 - was a common enough result to warrant more research. 


\section{CONCLUSIONS}

Though the levels of BPA in thermal paper do not pose a significant health hazard to the general population, the chemical should still be avoided as much as possible, especially since there are alternative that could be used. Still, the public should be informed that the chemical is used in many applications in case they may wish to avoid it. Retail workers may wish to speak to management about changing the thermal paper they must handle to a product without BPA.

There is a general trend to products using replacement chemicals already; many food containers are marketed with a "BPA Free" label, though it is unsure what health effects the replacement chemical may have on the human body.

\section{ACKNOWLEDGEMENTS}

The author would like to thank the project supervisor, Vanessa Karakilic, for the advice and guidance throughout this project.

The author would also like to thank Kevin Soulsbury for his help in determining the best method for testing for BPA, and helping with the chemical analysis 


\section{References}

1. Rubin B. Bisphenol A: an endocrine disruptor with widespread exposure and multiple effects. J Steroid Biochem [Internet]. 2011 Oct [cited 2015 Oct 10]; 127(1/2): 27 34. Available from: https://www.ncbi.nlm.nih.gov/pubmed/2160 5673

2. IBM. [Internet]. Research Triangle Park (NC): IBM Corporation; c2004. 2004 August [cited 2015 Oct 10). Available from: http://www-

03.ibm.com/products/retail/de/resources/whi te_paper_print_en.pdf

3. The Council for Thermal Paper Facts [Internet]. [Publisher unknown]: The Council for Thermal Paper Facts; [2010] [cited 2015 Oct 10]. Available from: http://www.thermalpaperfacts.org/factsabout-thermal-paper

4. Hormann A, vom Saal F, Nagel S, Stahlhut R, Moyer C, Taylor J, et al. Holding thermal receipt paper and eating food after using hand sanitizer results in high serum bioactive and urine total levels of bisphenol A (BPA). Plos ONE [Internet]. 2014 Oct, [cited 2015 October 20]; 9(10): 1-12. Available from: http://journals.plos.org/plosone/article?id=10 .1371 journal.pone.0110509

5. Chyczewski L, Niklinski J, Pluygers, E. Endocrine disruptors and carcinogenic risk assessment. Bialystok, Poland; 2002. 372.

6. Vogel, S. The politics of plastics: the making and unmaking of bisphenol A "safety". Am J Public Health [Internet]. (2009, Nov), [cited 2015 October 12]; 99(Suppl 3): S559-S566.
Available from US National Library of Medicine National Institutes of Health: http://www.ncbi.nlm.nih.gov/pmc/articles/P MC2774166/

7. Government of Canada. Chemical Substances. Bisphenol A - fact sheet. Ottawa: Government of Canada, 2008 [cited 2015 Oct 12]. Available from:

http://www.chemicalsubstanceschimiques.gc. ca/fact-fait/bisphenol-a-eng.php

8. Canada. Statistics Canada. Bisphenol A concentrations in Canadians, 2009 to 2011. Ottawa: Statistics Canada, 2013 [cited 2015 Oct 13]. Available from : http://www.statcan.gc.ca/pub/82-625$\mathrm{x} / 2013001 /$ article/11778-eng.htm

9. Schwartz A, Landrigan P, Taylor J, vom Saal F, Welshons W, Laffont C, et al. Bisphenol A in thermal paper receipts: an opportunity for evidence-based prevention. Environl Health Persp [Internet]. 2012 Jan, [cited 2015 October 14]; 120(1): A14-A15. Available from Academic Search Complete: URL

10. Biedermann S, Tschudin P, Grob K. Transfer of bisphenol A from thermal paper to the skin. Anal Bioanal Chem [Internet]. (2010, Sep), [cited 2015 October 15]; 398(1): 571576. Available: https://www.ncbi.nlm.nih.gov/pubmed/2062 3271

11. Braun J, Yolton K, Dietrich K, Hornung R, Xiaoyun Y, Lanphear B, et al. Prenatal bisphenol A exposure and early childhood behavior. Environ Health Persp [Internet]. 2009 Dec, [cited 2015 October 20]; 117(12): 1945-1952. Available from: https://www.ncbi.nlm.nih.gov/pubmed/2004 
9216

12. Government of Canada. Health Canada. Health risk assessment of bisphenol A from food packaging applications. Ottawa: Health Canada, 2008 [cited 2015 October 20]. Available from: http://www.hc-sc.gc.ca/fnan/securit/packag-emball/bpa/bpa_hra-erseng.php

13. Canada bans bisphenol A in baby products. Nature [Internet]. 2008 Oct 23, [cited 2015 October 13]; 455 (7216): 1020. Available from:

http:/www.nature.com/news/2008/081022/f ull/4551020a.html

14. Government of Canada. Healthy Canadians. Bisphenol A (BPA). Ottawa: Government of Canada, 2013 [cited 2015 October 12].

Available from:

http://healthycanadians.gc.ca/healthy-livingvie-saine/environment-

environnement/home-maison/bisphenol_aeng.php

15. MicroSolv. Extended application note bisphenol A. 2015 April [cited 2014 December 12]. Available from: http://kb.mtcusa.com/getAttach/814/AA02601/A327+BPA+Bidentate+C8+Receipts+ $\mathrm{NCR}+$ Paper+RP.pdf

16. Geens T, Goeyens L, Kannan K, Neels H, Covaci A. Levels of bisphenol-A in thermal paper receipts from Belgium and estimation of human exposure. Science Total Environ [Internet]. 2012 Oct [cited 2016 February 19]; 435-43630-33. Available from: https://www.ncbi.nlm.nih.gov/pubmed/2284 6760

17. Goldinger D, Demierre A, Zoller O, Rupp H,
Reinhard H, Bourqui-Pittet $\mathrm{M}$, et al. Endocrine activity of alternatives to BPA found in thermal paper in Switzerland. Regul Toxicol Pharm [Internet]. 2015 Apr [cited February 16, 2016]; 71(3): 453-462. Available from:

https://www.ncbi.nlm.nih.gov/pubmed/2557 9646

18. Konkel, L. Thermal reaction: the spread of bisphenol S via paper products. Environ Health Persp [Internet]. 2013 March [cited 2016 February 19]. Available from: http://ehp.niehs.nih.gov/121-a76/ 